\title{
A Speed Control of DC Motor with PWM Using Microcontroller in Hardware in Loop
}

\author{
S. Reeba Rex ${ }^{1^{*}}$, Mary Synthia Regis Praba ${ }^{2}$ \\ ${ }^{1}$ Department of ECE, Mar Ephraem College of Engineering and Technology, Elavuvilai, India. \\ ${ }^{2}$ Department of EEE, Noorul Islam University, Thuckalay, India. E-mail:regisprabha@gmail.com \\ *Corresponding author E-mail:reebarex@gmail.com
}

\begin{abstract}
This paper presents an implementation of a microcontroller based boost converter to maintain constant speed of a DC motor. The optimised values namely kp,ki,kd of the Boost Converter are taken from firefly algorithm[10] and implemented using microcontroller. Pulse width modulation (PWM) is a procedure to generate changeable pulse width with different duty cycle. The PWM signal reduces the switching losses. This paper presents a DC motor speed controller where PID Controller is used where the optimized values of $\mathrm{kp}, \mathrm{ki}, \mathrm{kd}$ are taken from firefly algorithm[10]. The PWM pulse width will alter the speed of the motor. The motor voltage and revolutions per seconds (RPS) obtained at different duty cycle rates. With increase in duty cycle, further voltage is applied to the motor. This gives stronger magnetic flux in the armature windings and to enhance revolutions per seconds. The characteristics and concert of the DC motor speed control system was discussed. In this paper, a PIC microcontroller is designed with a DC-DC boost converter for the motor speed controller system. Finally to improve the graphical result we design the hardware in loop method using matlab.
\end{abstract}

Keywords: Boost converter, duty cycle, pulse width modulation, proportional integral derivative.

\section{Introduction}

Kinattingal et.al proposes a converter which uses pid controller whose parameters are optimised using queen bee assisted genetic algorithm. Here line and load regulation is monitored for step change in output and input. Here the settling time, peak overshoot and under shoot are analysed[1]. Brain $\mathrm{R}$ Copeland proposed Ziegler Nichols Tuning is used for tuning PID controller. This method line and load regulation is monitored for step change in input and output. Here the settling time, peak overshoot and under shoot are analysed. Dynamic response of the controller is not good and the convergence with best solution is poor. For this reason we need to go for other optimisation algorithm[2]. Here fuzzy logic implementation of boost DC-DC converter is analysed and the line and load regulation is monitored[3]. Here pulse width modulated is used for sliding mode controller for boost converter is discussed[4].Here the continuous and discontinuous modes of a boost converter is discussed. Further the duty cycle variation with respect to input voltage is discussed[5].Here various method like sliding mode, PI Integral, fuzzy logic implantation and line, load regulation are monitored[6]. Rick zaitu, et. al., proposed small signal loop analysis of DC-DC boost converter using TPS61030 system to meet dynamic load variation. The PID controller was tuned to tune the proportional, derivative and integral gains yielding a minimum overshoot and low ripple content. The controller modifies the duty cycle of the boost converter in terms of input voltage and loading variations such that it produces a stable output voltage[7]. Tang, et. al., designed a Fuzzy controller to regulate a boost converter whose operation was verified by simulation. The output of Fuzzy and PID controllers are compared for various aspects like output transient, line and load regulation.
The Fuzzy controller output shows reduced settling time. In order to obtain dynamic performance and less steady state error fuzzy logic controller is carried out for DC-DC converters[8]. In CCM and DCM the linear model for PWM switch is obtained with the help of ideal diode and switch[9]. Reeba et.al., suggested various optimisation algorithms namely cuckoo search, frog leaping and cuckoo search algorithm are discussed. From the best performed algorithm that is firefly algorithm the optimised values are taken and planned to implement a converter for the optimized values got from the design[10].

In this paper, an boost converter is implemented for the optimized values obtained from firefly algorithms[10].In section A deals with boost converter basics with respect to duty cycle and CCM,DCM is discussed. Section B deals with boost converter and modeling of controller design is discussed. Section C deals with flowchart of hardware implementation. Section D deals with hardware implementation of boost converter. 


\section{Boost Converter}

The voltage at the output of the boost converter can be altered by varying the duty cycle. If on time is more, output voltage will be more. If on time is less, output voltage will be low. If there is no loss in inductor then input is converted to output with no power loss and is $100 \%$ efficient conversion. Figure 2 shows variation of duty cycle. A $50 \%$ duty cycle means pulse width is on for $50 \%$ and off for $50 \%$.

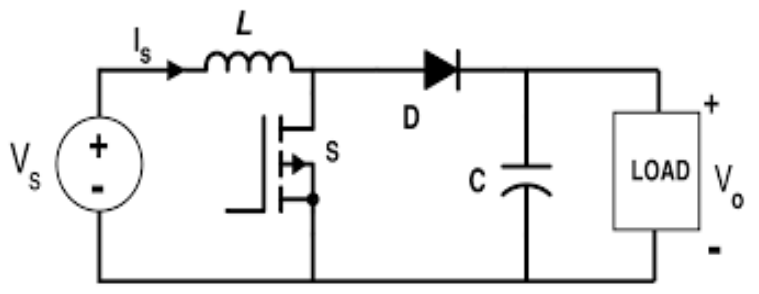

Fig. 1: Boost converter

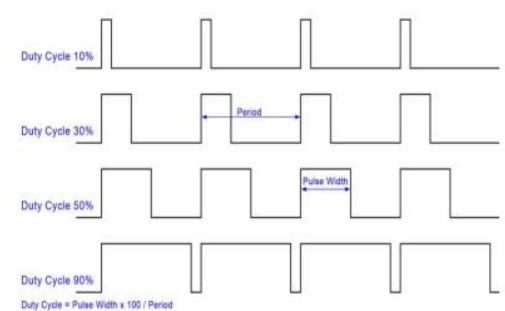

Fig. 2: Duty cycle

There are two modes of operation in boost converter. They are continuous conduction mode $(\mathrm{CCM})$ and discontinuous conduction mode (DCM). In CCM the inductor current never ceases to zero. In DCM the inductor current ceases to zero. A boost converter operates in continuous mode if inductor current by no means ceases to zero. Figure 3 shows CCM and DCM mode.
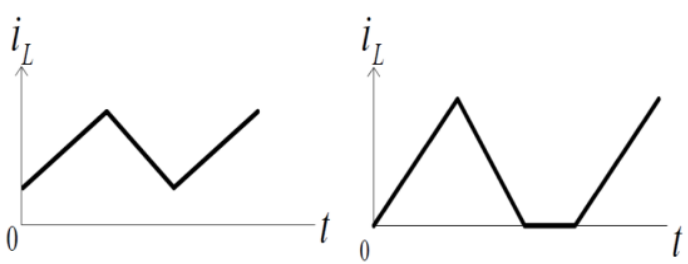

Fig. 3: CCM and DCM mode

\section{Boost Converter Analysis}

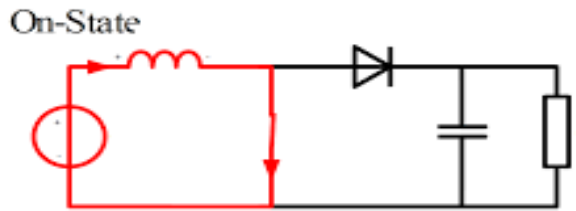

Off-State

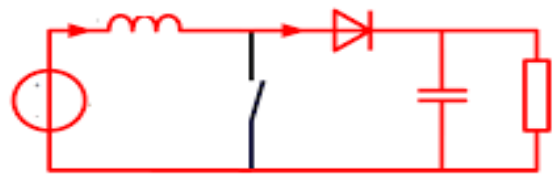

Fig. 4: Boost converter(on/off state)

- When on, the switch is shut, MOSFET is on and the current over the inductor increments.

- In the off express the switch is open, MOSFET is off and the vitality put away in the inductor moves through diode, capacitor and load. In the event that the lift converter works in nonstop conduction mode then the current through the inductor never tumbles to zero. In irregular mode the charge in the inductor is released before the cycle. ends.

Boost Converter uses MOSFET as its switching element, when it is closed its reverse biases the diode and the voltage across the inductor is identical to input voltage $V_{\text {in }}$ and the inductor voltage is denoted by $V_{L}$. The current through the inductor is given by $I_{L}$

Therefore $V_{L}=\mathrm{L} V_{L}=V_{L}=\frac{d I_{L}}{d t} V_{L}=V_{\text {in }} V_{L}=V_{\text {in }}$

$$
\text { Also } V_{L}=V_{\text {in }} V_{L}=\mathrm{L} \frac{d I_{L}}{d t}
$$

When the switch is open the diode will be in on state due to the current stored in the inductor.

Therefore $V_{\text {in }}=V_{L}+V_{\text {out }}$

$$
\text { Also } \frac{V_{L}}{L}=\frac{d I_{L}}{d t}
$$

The duty cycle with regard to output voltage is given by

Where $\mathrm{D}$ refers to duty cycle

$$
V_{\text {out }}=\frac{V_{\text {in }}}{1-D}
$$

The duty cycle with regard to output voltage is given by

Where $\mathrm{D}$ refers to duty cycle

$$
V_{\text {out }}=\frac{V_{\text {in }}}{1-D}
$$

The boost converter is designed with closed loop using MOSFET switch. The converter is designed with following specification: input voltage $\mathrm{Vin}=12 \mathrm{~V}$; switching frequency $\mathrm{fs}=2 \mathrm{kHz}$; inductance $=33 \mathrm{mH}$, capacitance $=1000 \mathrm{pF}$ and load resistance $100 \mathrm{Ohm}$ and output voltage $=48 \mathrm{~V}$.

$\left[\begin{array}{c}\dot{x_{1}} \\ \dot{x_{2}}\end{array}\right]=\left[\begin{array}{cc}\frac{r_{L}}{L} & 0 \\ 0 & \frac{-1}{c\left(r_{C}+R_{L}\right)}\end{array}\right]\left[\begin{array}{l}x_{1} \\ x_{2}\end{array}\right]+\left[\begin{array}{c}\frac{1}{L} \\ 0\end{array}\right] V_{\text {in }}$

The voltage, at the output of the boost converter when the switch is on is given by

$v_{0}=\left[\begin{array}{ll}0 & \frac{R_{L}}{\left(R_{L}+r_{c}\right)}\end{array}\right]\left[\begin{array}{l}x_{1} \\ x_{2}\end{array}\right]$

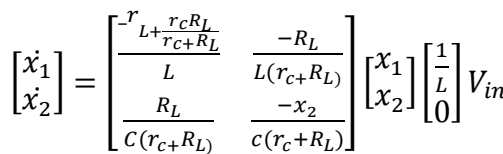

The output voltage in this mode is

$$
v_{0}=\left[\begin{array}{ll}
\frac{r_{c} R_{L}}{r_{c+} R_{L}} & \frac{R_{L}}{\left(R_{L}+r_{c}\right)}
\end{array}\right]\left[\begin{array}{l}
x_{1} \\
x_{2}
\end{array}\right]
$$

The error is given by

$e(t)=\widetilde{V_{O}}-v_{O}$

Thus the error signal is the comparison of actual and reference voltage.

Let $F(\theta)$ denotes the minimization function which is used for optimization. The aim is to minimize settling error, steady state error,peak overshoot and undershoot. The function is written us $\mathrm{F}(\theta)=\sum_{t=0}^{t s} \mathrm{e}(\mathrm{t})$

$\theta=[\mathrm{Kp}, \mathrm{Ki} \& \mathrm{Kd}]$ is the controller ts is the start up time.

\section{Flow Chart}

First we need to set the command from the $\mathrm{PC}$ to the microcontroller. Then compute the error. Based on this generate PWM pulse and give to boost converter. From that the speed of the motor is controlled and speed sensor is set to sense the speed. Constant speed can be maintained using microcontroller by varying PWM pulse. 


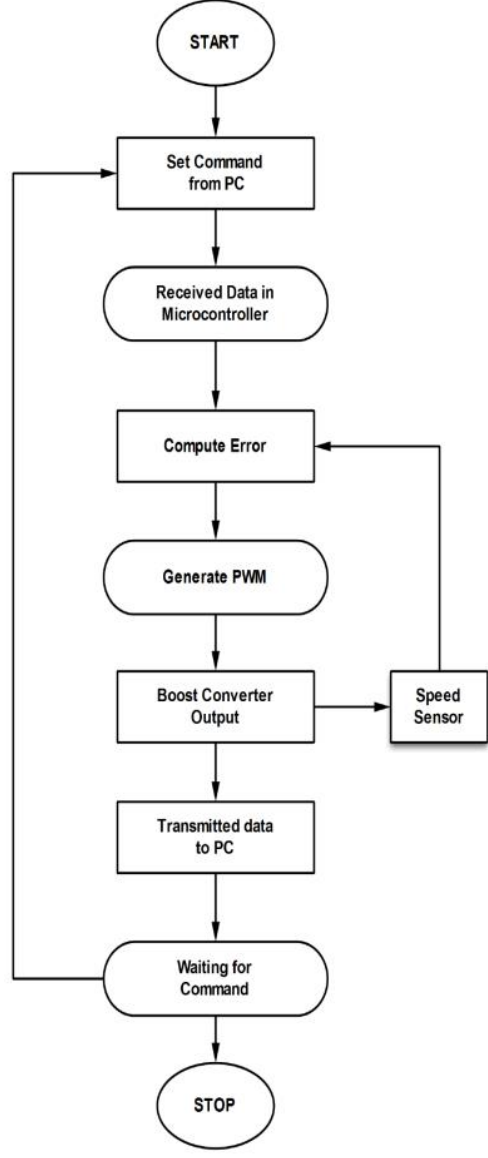

Fig. 5: Flow chart of hardware design

\section{Hardware Design and Implementation}

\section{Block diagram}

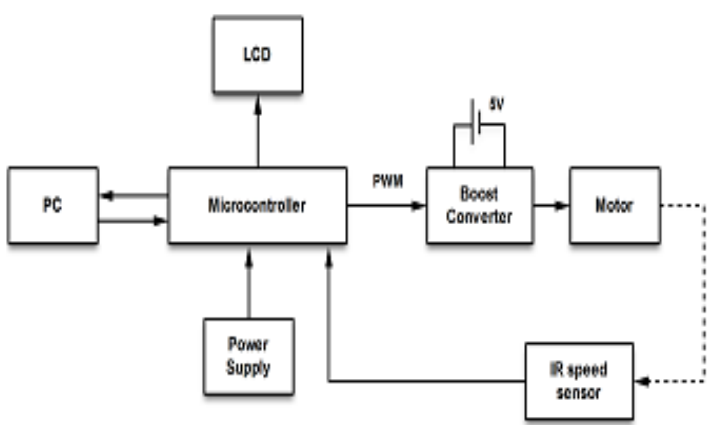

Fig. 6: Block diagram of boost converter

The Set point and the Time sample are given to the Kit using the MATLAB front end designed as GUI. The MATLAB session and the kit are synced using the USB to TTL converter which is connected to the USB port of the Microcontroller. The serial port receives the MATLAB Command and gives it to the Microcontroller. The Microcontroller produces the PWM based on the set point. The Boost Converter gets the PWM and the boost process is driven using the PWM received. The Boost Converter output is attached to the load. The load given is the DC Motor. The Speed Sensor senses the Speed and it transmits the Speed to the PC. The Real time speed received is plotted to display the Time vs Speed Graph.

\section{Hardware section}

- $\quad$ PIC Microcontroller
- Boost Converter

- LCD

- Regulated Power Supply

- IR Transmitter

- DC Motor

- USB to TTL

\section{PIC microcontroller}

PIC is the acronym of Peripheral Interface Microcontroller. It have certain features. It uses Harvard architecture and has fixedlength instructions. Here RAM acts as register in both input and output. Here the PIC Microcontroller is used to interface the computer with boost converter, which will further monitor the speed of DC motor.

\section{Speed sensor}

Speed sensor is the electronic gadget used to screen the speed of motors. Here a speed sensor is utilized to screen the execution of DC motor. Based on the perception of the speed sensor the microcontroller will charge for steady speed control.

\section{$L C D$}

LCD is the liquid-crystal display (LCD) that uses the light adjusting properties of liquid crystals. Liquid crystals don't produce light straightforwardly. The main benefit of LCD display is it devour less electrical power.

\section{Regulated power supply}

A power supply is a device that provides electric power to an electrical load. managed power supply provides fixed voltage to the converter.

\section{Motor}

A DC motor converts direct current electrical power into mechanical power. Here dc motor is interfaced to the boost converter and the speed is controlled using microcontroller.

USB 232

The USB to RS232 device board may be a PIC microcontroller based mostly device that receives a USB signal from a laptop and converts the signal to an RS232 output. The sign is sent to anyone of 3 serial ports.USB specification has a pair of full-speed $12 \mathrm{Mbps}$ five pins for three.3V, RST, TXD, RXD, GND \& 5V.Baud rates: three hundred rate to one.5 Mbps.

\section{Pin Diagram}

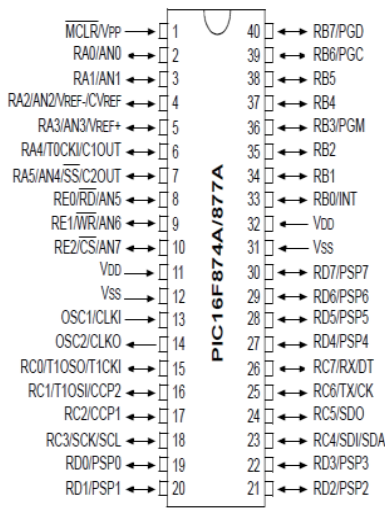

Fig. 7: Pin diagram 


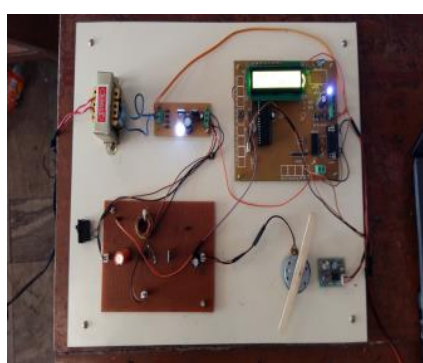

Fig. 8: Hardware of boost converter

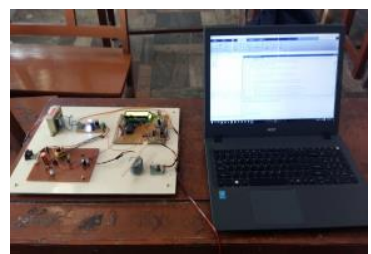

Fig. 9: Hardware of boost converter interfaced with system

Table I: Dynamic Response of Boost Converter with Bees GA, Frog Leap (FL), Cuckoo Search(CS), Fire-Fly (FF) [10]

\begin{tabular}{|l|l|l|l|l|}
\hline Parameter & QBAG & FL & CS & FF \\
\hline $\mathrm{kp}$ & 6.0527 & 19.0253 & 15 & 9.3173 \\
\hline $\mathrm{ki}$ & 17.8612 & 12.2334 & 12 & 5.8082 \\
\hline $\mathrm{Kd}$ & 1.1588 & 1.6206 & 12 & 0.2452 \\
\hline Rise time & 0.1781 & 0.1170 & 0.0675 & 0.0481 \\
\hline Settling Time & 1.3805 & 1.9005 & 1.1490 & 0.2994 \\
\hline Settling Min & 43.1141 & 42.9281 & 43.0328 & 42.9268 \\
\hline Settling Max & 53.0372 & 49.9417 & 49.3554 & 48.9981 \\
\hline Overshoot & 10.0867 & 4.0798 & 2.9149 & 1.9100 \\
\hline Undershoot & 0.0066 & 0.0066 & 0.0066 & 0.0066 \\
\hline Peak & 53.0372 & 49.9417 & 49.3554 & 48.9981 \\
\hline Peak time & 0.7944 & 0.6714 & 0.5404 & 0.4765 \\
\hline $\begin{array}{l}\text { Integral } \\
\text { Square Error }\end{array}$ & $9.4095 \mathrm{e}+05$ & $5.8721 \mathrm{e}+05$ & $4.3067 \mathrm{e}+05$ & $3.7330 \mathrm{e}+05$ \\
\hline $\begin{array}{l}\text { Integral } \\
\text { Absolute } \\
\text { Error }\end{array}$ & $1.2464 \mathrm{e}+05$ & $9.3168 \mathrm{e}+04$ & $5.8017 \mathrm{e}+04$ & $4.7626 \mathrm{e}+04$ \\
\hline
\end{tabular}

\section{Results and Discussion}

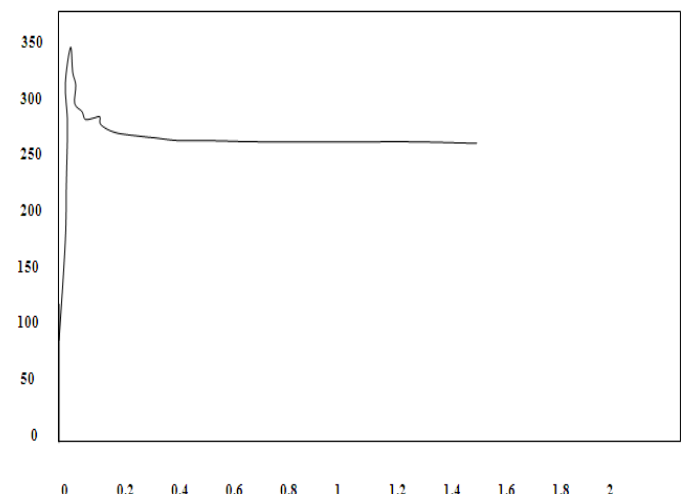

Fig. 10: Speed vs time graph

The designed control system with optimized values of kp,ki,kd taken from [10] can control the motor speed very quickly. The main benefit of using DC motors in today's world is the capacity is to control the speed with no trouble. This paper is about controlling the speed of DC motor by using micro Controller. The motor speed (current value) reaches to set value in a short time and used for speed control. By analyzing the simulation results we can conclude that many of the desired characteristics such as rise time and overshoot improve. The results of simulation and hardware implementation show the superior performance of the system.[11][12]

\section{Conclusion}

This paper presents a DC motor speed controller where PID Controller is used where the optimized values of $\mathrm{kp}, \mathrm{ki}, \mathrm{kd}$ are taken from firefly algorithm[10].The PWM pulse width will alter the speed of the motor. The motor voltage and revolutions per seconds(RPS) obtained at different duty cycle rates. With increase in duty cycle, further voltage is applied to the motor. This gives stronger magnetic flux in the armature windings and to enhance revolutions per seconds. The characteristics and concert of the DC motor speed control system was discussed. In this paper, a PIC microcontroller is designed with a DC-DC boost converter for the motor speed controller system. Finally to improve the graphical result we design the hardware in loop method using matlab.

\section{References}

[1] Sundareswaran K \& Sreedevi VT, "Boost Converter Controller Design Using Queen-Bee-Assisted GA", IEEE Trans. Ind. Electron., Vol.56, No.3, (2009), pp.779-783.

[2] Copeland BR, "The design of PID Controllers using Ziegler Nichols Tuning", (2008).

[3] Taeed F, Salam Z \& Ayob SM, "Implementation of Single Input Fuzzy Logic Controller for Boost DC to DC Power Converter", IEEE International Conference on Power and Energy (PECon2010), (2010), pp.797-802.

[4] Tan SC, Lai YM \& Tse CK, "Implementation of pulse-widthmodulation based sliding mode controller for boost converters", IEEE Power Electronics Letters, Vol.3, No.4,(2005), pp.130-135.

[5] Mohan N, Undeland TM \& Robbins WP, Power Electronics, 2nd ed. New York: Wiley, (2003).

[6] Raviraj VSC \& Sen PC, "Comparative study of proportionalintegral, sliding mode, and fuzzy logic controllers for power converters", IEEE Trans. Ind. Appl., Vol.33, No.2, (1997), pp.518524.

[7] Zaitsu R, "Voltage mode boost converter small signal control loop analysis using the TPS61030", Texas Instruments, Appl. Report SLVA274A, (2009).

[8] Tang KL \& Mulholland RJ, "Comparing Fuzzy logic with classical controller design", IEEE Transactions on systems, Man and cybernetics, Vol.6, (1987), pp.1085-1087.

[9] Vorperian V, "Simplified Analysis of PWM Converters Using the Model of the PWM Switch,Parts I (CCM) and II (DCM)", IEEE Transactions on Aerospace and Electronic Systems, Vol.26, No.3, (1990).

[10] Reeba Rex S \& Mary Synthia Regis Praba DM "Modern Optimization based Controller Design for Boost Converter Using Soft Computing Techniques", Jour of Adv Research in Dynamical \& Control Systems, Vol.10, No.2, (2018).

[11] Iskakova, M Sarsembayev, Z Kakenova (2018). Can Central Asia be integrated as asean? Opción, Año 33. 152-169.

[12] G Cely Galindo (2017) Del Prometeo griego al de la era-biós de la tecnociencia. Reflexiones bioéticas Opción, Año 33, No. 82 (2017):114-133 